\title{
A Selective Medium for Pyocyanin-dependent Fast Electrochemical Detection of Pseudomonas aeruginosa in Environmental Microbial Samples
}

\author{
Shuihong Lit ${ }^{1,2, *}$, Qianqian Mou ${ }^{2}$, Nuozhou Feng ${ }^{2}$, Polly H.M.Leung ${ }^{2}$ \\ ${ }^{1}$ Hunan Province Cooperative Innovation Center for Molecular Target New Drug Study, University of \\ South China, Hengyang 421001, China \\ ${ }^{2}$ Department of Health Technology and Informatics, the Hong Kong Polytechnic University, Hong \\ Kong 999077, China \\ *E-mail: zhoubaoxi520@163.com
}

doi: $10.20964 / 2018.04 .20$

Received: 23 October 2017 / Accepted: 24 January 2018 / Published: 6 March 2018

\begin{abstract}
In this work, a selective medium was developed for pyocyanina-dependent qualitative detection of Pseudomonas aeruginosa in raw microbial samples using electrochemical analysis. To obtain an optimum nutritive formulation, the effect of different media (BYEB, LB, SDB, MHB, TSB, and NB), positive ions $\left(\mathrm{K}^{+}, \mathrm{Na}^{+}, \mathrm{Ca}^{2+}, \mathrm{Fe}^{3+}\right.$, and $\mathrm{Mg}^{2+}$ ) and selected additives (1-naphthylamine, acetamide, and benzylpenicillin sodium) on the amount of synthesized pyocyanin were investigated and compared. NB was found to be the most favourable medium for the electrochemical detection of pyocyanin, and $\mathrm{Mg}^{2+}$ was shown to be the most effective supporting additive ion for the detection. 1-Naphthylamine was shown to be the most effective supporting antibiotic reagent when supplied in the medium to enhancing the presence of pyocyanina compared to the other two antibiotics. The results indicated that the improved selective medium (ISM) can effectively inhibit/limit the growth of various microorganisms other than $P$. aeruginosa and obviously enhance the production of pyocyanin in environmental samples that contained $P$. aeruginosa. This study provided a method for simple and fast electrochemical detection of $P$. aeruginosa in complex microbial samples.
\end{abstract}

Keywords: Pseudomonas aeruginosa; pyocyanin; electrochemical detection; selective medium; differential pulse voltammetry

\section{FULL TEXT}

(C) 2018 The Authors. Published by ESG (www.electrochemsci.org). This article is an open access article distributed under the terms and conditions of the Creative Commons Attribution license (http://creativecommons.org/licenses/by/4.0/). 